\title{
O que é necessário para que a Interseccionalidade possa vir a ser?
} What's Necessary so that Intersectionality Can Become?

\author{
Ísis Aparecida Conceição' (iD) 0000-0003-0558-2508 \\ 'Universidade Internacional da Lusofonia Afro-Brasileira, São Francisco do Conde, BA, \\ Brasil.43900-000 - ihlmales@unilab.edu.br
}

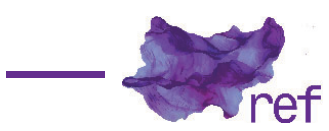

COLLINS, Patricia Hill.

Intersectionality as critical social theory.

Durham and London: Duke University Press, 2019.

A interseccionalidade popularizou-se contemporaneamente, popularização que trouxe no bojo o debate sobre o que vem a ser e quem seria legítimo a dizer o que ela é. No cenário jurídico brasileiro, em 2018, a prova do concurso da magistratura federal do Tribunal Regional Federal da terceira região trouxe, em uma de suas questões de múltipla escolha, definição do termo jurídico Interseccionalidade. ${ }^{1}$ Em ano anterior, a prova objetiva do $29^{\circ}$ concurso do Ministério Público Federal também trazia, em uma de suas questões de múltipla escolha, o conceito cunhado pela juspensadora da escola de Teoria Crítica Racial, Kimberlé Williams Crenshaw. ${ }^{2}$

O Livro de Patricia Hill Collins, Intersectionality as critical social theory (2019), sucede sua obra em coautoria com Sirma Bilge, Intersectionality, publicado em 2016, ambos ainda sem tradução para o português. Na obra de 2016 Bilge e Collins afirmavam, já na introdução, que o livro deveria ser compreendido como um convite ao ingresso nas complexidades da interseccionalidade, como oferta de ferramentas navegacionais um mapa geográfico para movimentar-se e fazer descobertas no vasto terreno da interseccionalidade (Sirma BILGE; Patricia Hill COLLINS, 2016, p. 8), explicitando que a interseccionalidade permitiria descobertas, mas

\footnotetext{
1 "A narrativa dos direitos humanos tem sido no sentido de ampliar a sua proteção. A esse respeito, "o termo Interseccionalidade foi criado por Kimberlé Crenshaw para retratar a incidência dos mais diversos fatores de discriminação em um caso concreto. Tal necessidade foi verificada a partir do momento em que o caráter universal dos direitos humanos mostrou-se insuficiente para tutelar e salvaguardar os direitos humanos" (cf. PAIVA, Caio Cezar; HEEMANN, Thimotie A. Jurisprudência Internacional de Direitos humanos. 2. ed. 2017, p. 587). Fatores de discriminação não resolvidos, ou quando enfrentados de forma desconexa, se entrelaçam, aumentando a opressão em grandeza exponencial. Foi o que ocorreu com a violação de direitos de mulher refugiada, negra, pobre, analfabeta, homossexual e com filha portadora de HIV, a quem foi negada pelo Estado o direito a educação. Ao apreciar essa situação, o Sistema Interamericano de Direitos Humanos reconheceu pela primeira vez o fenômeno da Interseccionalidade. Trata-se do julgamento do caso:" COMISSÃO DO CONCURSO PÚBLICO PARA PROCURADOR DA REPÚBLICA. Prova Objetiva do $29^{\circ}$ Concurso Público de Procuradores da República. Brasília: Secretaria do Concurso, 2017.

2 "A Interseccionalidade dos direitos humanos, por detectar diferentes formas de opressão e tratamento discriminatório baseado em raça, gênero, condição social, idade, orientação sexual, entre outras formas de identidade socia que se inter-relacionam, exige reparações às vítimas que levem em conta estas especificidades.". COMISSÃO DO XIX CONCURSO DO TRIBUNAL REGIONAL FEDERAL DA TERCEIRA REGIÃO, 2018. Prova Objetiva do XIX Concurso Público Para o Provimento de Cargos de Juiz Federal Substituto. São Paulo: Comissão de Concurso do XIX Concurso, 2018.
} 
não seria a descoberta. Aquela incursão no "mundo da interseccionalidade" foi concluída com as autoras expressando sua preocupação face à "formalização/institucionalização" da interseccionalidade de forma que terminasse por se tonar uma categoria colonizadora nos espaços tradicionais de saber, sob o risco de tornar-se uma ferramenta em conflito com a busca de justiça social (BILGE; COLLINS, 2016, p. 203).

$\mathrm{Na}$ obra de 2019, aparentemente mais confortável com as constatadas disputas epistêmicas ao redor da categoria, Collins conclui que a "Interseccionalidade oferece uma janela para pensar sobre o significado de ideias e ações sociais na promoção de mudança social [...]"3 (COLLINS, 2019, p. 1) e que a "Interseccionalidade não é o único projeto de conhecimento que se envolve com a resolução de problemas sociais, mas é aquele que dialoga com as complexidades de um mundo social em mudança [...]"4 (COLLINS, 2019, p. 2). Parece que essa complexidade é a própria disputa entre pessoas subalternizadas pelos espaços cedidos no processo de inclusão liberal.

Collins, após deparar-se com os desafios de elaboração do Syllabus para uma disciplina de pós-graduação sobre interseccionalidade, passou, na disciplina, a percorrer uma longa trajetória, que tem lugar até os dias atuais, de esforços por responder à pergunta sobre o que vem a ser a interseccionalidade. Collins insiste em não responder definitivamente o que é a interseccionalidade, mas, dentre as várias definições listadas, destaca-se:

[...] uma forma de saber de resistência para desestabilizar mentalidades conservadoras, desafiar poderes opressores, pensar transversalmente toda arquitetura de desigualdades estruturais e oportunidades de vida assimétricas, em busca de um mundo mais justo [... $]^{5}$ (Vivian MAY apud Patricia Hill COLLINS, 2019, p. 119).

Em Interseccionalidade como Teoria Crítica Social (tradução livre), a autora convida todas as pessoas a participarem da disputa de poder epistêmica, inclusive as não acadêmicas, ativistas detentoras dos saberes não reconhecidos pelos espaços formais, de maneira a garantir que a categoria cunhada por Crenshaw, e popularizada durante a Conferência de Durban de 2001 , seja "[...] salva dos estudos da interseccionalidade [...]"6, conforme clama por Bilge no título de seu artigo (BILGE, 2013).

A obra de Collins não é fácil para desconhecedoras/es da linguagem do espaço das disputas pelo poder de afirmar o que é e o que não é a ciência, o saber e o conhecimento. Esse traço da obra pode causar estranheza àquelas que compreendem interseccionalidade exclusivamente como práxis, mesmo afirmando a autora que o saber produzido pela Interseccionalidade - teoria ou ferramenta - transpõe o espaço da etérea e abstrata torre de marfim da academia universitária e manifesta-se também no ambiente das lutas de resistência pelo direito de existir dos projetos dissidentes, antirracistas, decoloniais, feministas. O livro é um calhamaço sistematizante de teorias das ciências sociais que parece ambicionar formular uma nova linha teórico-epistemológica, uma leitura avançada, com esforços de diálogo junto aos movimentos contra-hegemônicos. Como afirma a autora ainda na introdução, um livro desafiador de ser escrito e, consequentemente, de compreensão desafiadora para quem o ler.

Logo no início, Collins apresenta o paradigma, o conceito, a abordagem, a ferramenta heurística, a teoria, a categoria jurídica, da interseccionalidade. Ela também destaca a premissa de que sistemas de poder assemelhados constroem-se mutuamente, relações de poder interseccionais produzem desigualdades complexas. Na medida que o lugar social modela experiências de mundo, solucionar problemas sociais exige observar o contexto, e que tudo isso informa a análise intersecional; portanto, não sendo simples.

Defende que toda análise será incompleta se ignorar a interação entre os marcadores sociais relevantes para a vida social, marcadores que não se tratam da preferência de alguém por um determinado sabor de sorvete ou da cor dos olhos de uma pessoa, haja vista serem marcadores de relações de poder que moldam as relações sociais. São categorias justificadoras de injustiças sociais.

O livro é formalmente disposto de uma introdução, oito capítulos, organizados em quatro partes, e um epílogo. Na introdução, de forma muito leal, Collins declara que acredita estar observando o processo histórico de formação de uma nova linha teórica da sociologia com potencial revolucionário e que pretende, assim, desenvolver essa tese. ${ }^{7}$ Ou seja, já na introdução

\footnotetext{
${ }_{3}$ Tradução do original: "Intersectionality offers a window into thinking about the significance of ideas and social action in fostering social change".

${ }^{4}$ Tradução do original: "Intersectionality is not the only knowledge Project that engages in social problem solving, but it is one that speaks to the complexity of changing social world.".

${ }_{5}$ Tradução do original: "a form of resistant knowledge developed to unsettle conventional mindsets, challenge oppressive power, think through the full architecture of structural inequalities and asymmetrical life opportunities, and seek a more just world".

"Tradução do original: "Intersectionality Undone. Saving Intersectionality from Feminist intersectionality Studies".

7 Collins, em sua atenta observação das sociedades ao constatar as disputas no contexto dos estudos da interseccionalidade, percebeu o momento de apresentar seus estudos sobre justiça social e feminismo negro,
} 
do livro a autora informa que não pretende responder o que vem a ser a interseccionalidade, mas apresentar, a quem ignora as escolas de pensamento teórico contra-hegemônicas, o que the parece compor essa teoria "em processo de formação" (COLLINS, 2019, p. 08). A interseccionalidade permitiria observar como a análise teórico-crítica e a ação de movimentos sociais dialogam e podem dialogar mais eficazmente entre si. Ao optar por classificar a interseccionalidade como um tipo de teoria crítica, Collins disputa também o poder epistêmico de dizer o que é o gênero que comporta a espécie.

Na primeira parte, "Framing the Issues", Collins apresenta as definições que encontrou de interseccionalidade e algumas outras teorias selecionadas, as quais identifica como lentes críticas e necessárias para a compreensão da interseccionalidade como uma teoria crítica da sociedade. Identifica termos técnicos necessários para facilitar a leitura do livro.

No primeiro capítulo, "Intersectionality as Critical Inquiry", Collins desenvolve o admirável trabalho de observar, levantar, sistematizar e apresentar como as pessoas usam a palavra interseccionalidade e os fundamentos cognitivos da categoria, metafórico, holístico e paradigmático. Mostra como a interseccionalidade apresenta em si formas de pensar que são ao mesmo tempo metafóricas, holísticas e paradigmáticas. Destaca-se neste capítulo as seis ideias paradigmáticas da interseccionalidade que a formariam, listadas por Collins, as quais são: a relacionalidade, o poder, a desigualdade social, o contexto social, a complexidade, e a justiça social.

Em "What's Critical about Critical Social theory?" é descrita a diversidade de compreensões sobre o que vem a ser pesquisa crítica e escola de pensamento crítico e suas variadas implicações nos esforços de elaboração da interseccionalidade como teoria. São apresentadas três escolas relevantes - a escola de Frankfurt, a escola de estudos culturais britânica e a escola da teoria social francófona -, segundo a autora, para compreender essa empreitada de saber o que é teoria crítica, e as ferramentas úteis, de cada uma delas. São descritas, também, as possíveis contribuições, a participação desigual na produção de conhecimento que essas teorias podem promover, o que mitigaria seu traço de criticidade. Collins destaca dois importantes traços do ser crítico. O primeiro, familiar, refere-se à crítica de ideias; o segundo, diz respeito a uma compreensão de crítico menos popular como essencial e necessário.

A segunda parte, "How Power Matters", apresenta a práxis, destacadamente a de movimentos sociais, como fonte de produção de conhecimento. Descreve as ações e práticas dos movimentos sociais como espaços de produção de formas de aproximação e de intervenção no mundo que merecem ser reconhecidos como elemento central do processo de teorização da interseccionalidade. Pergunta como devem e como podem ser teorizadas as formas de resistência dos grupos subordinados a interseccionais formas de violências. Collins explicita a escolha por observar os movimentos de resistência e não de opressão.

No terceiro capítulo, "Intersectionality and Resistant Knowledge Projects", examina como os já reconhecidos e sedimentados projetos de resistência intelectual influenciam e sustentam o projeto de resistência intelectual que a interseccionalidade também pretende ser. Collins descreve sumariamente os estudos feministas, os estudos decoloniais e os estudos de teoria crítica racial, apresentando-os como dimensões desse projeto de resistência e exemplos prévios de esforços de teorização e criação de conceitos para os esforços contra hegemônicos.

No capítulo seguinte, "Intersectionality and epistemic Resistance", descreve os efeitos das dinâmicas de poder epistêmico nas possibilidades de existência dos projetos intelectuais de resistência. Isso porque a proposta da teoria da interseccionalidade - de ser uma ponte entre diversos produtores de saber, inclusive aqueles fora da academia, um tipo de teoria guarda-chuva, uma encruzilhada na qual os diversos grupos subalternizados se encontrariam e trocariam saberes de forma a aprimorarem suas estratégias de resistência contra hegemônica exige que a academia reconheça o saber dos sujeitos que atuam com a interseccionalidade, possibilitando a teorização da interseccionalidade, em toda a sua idiossincrasia, nos ambientes e espaços acadêmicos. Ao mesmo tempo, aponta a importância das estratégias de resistência ao silenciamento, de silenciamento de testemunhos e de atenuação de narrativas - o que classifica como "violências epistêmicas" ${ }^{-}$- que explicitam como funcionam as dinâmicas de poder dentro desses grupos produtores de saber.

A epistemologia hegemônica subvaloriza as experiências dos saberes de resistência por serem produto de pessoas subalternizadas, que usam sua experiência vivida de resistência a opressões cotidianas para produzir conhecimento. Por isso, a importância para a interseccionalidade da autoridade da narrativa pessoal/testemunho que, no capítulo, é avançados desde a obra Pensamento Negro feminista como uma linha teórica em uma área da sociologia, seu campo de ałuação.

${ }^{8}$ Tradução do original: "Some scholars have interpreted this tendency to disbelieve the stories of subordinated individuals as a form of epistemic violence. [...] tactics of epistemic violence operate within interpretative communities to police the cherished ideas of any given group. [...] epistemic violence operates through practices of silencing. Yet remaining silent does not signal consent; instead, it often results from being silenced." (COLLINS, 2019, p. 133, grifo do original). 
exemplificado pelo paradigmático caso de Anita Hill vs Clarence Thomas, cujas narrativas foram valoradas por um júri de homens brancos os quais concluíram pela maior autoridade da narrativa de Clarence, relacionalmente privilegiado em sua posição socioeconômica profissional e de gênero. Políticas de identidade e epistemologia do lugar de onde se fala reconhecem a importância da experiência para a produção de conhecimento. Esse é um dos capítulos mais reveladores do projeto intelectual de Collins, ao nosso ver.

A terceira parte, "Theorizing Intersectionality", lança atenção ao saber produzido pelo ativismo social como relevante aspecto da teorização da interseccionalidade. Apresenta uma diversidade de possíveis instrumentalizações da teoria a partir das lentes metodológicas do "dialogical engagement" (COLLINS, 2019, p. 14), observando analiticamente as dimensões constituintes da interseccionalidade. Essa parte teoriza a interseccionalidade com fundamento nas experiências de grupos subordinados. Para tanto, vale-se da prática das escolas contrahegemônicas como a do feminismo negro que demonstrou para as ciências a importância epistemológica e política de teorizar a partir de experiências, individuais e coletivas. Collins justifica que ser oprimida/o pelo colonialismo, patriarcado, racismo, nacionalismo e outros sistemas de poder assemelhados é um catalizador que leva as/os oprimidas/os a analisarem criticamente esses sistemas de poder (COLLINS, 2019, p. 12). Ademais, a autora clama pela atenção metodológica para que os esforços em estudar a interseccionalidade dentro das normas organizacionais prevalentes de poder epistêmico não deixem para trás os sujeitos subalternizados e desfaça os vínculos da interseccionalidade com os projetos de resistência.

No quinto capítulo, "Intersectionality, Experience, and Comunity", Collins afirma investigar como uma análise mais robusta da experiência e de comunidade pode lançar uma luz nas ações e práticas sociais como meio de produzir saber e delinear os limites da interseccionalidade. Utiliza-se do pensamento feminista negro e do pragmatismo norte-americano, em interação e diálogo, para obter diferentes ângulos de vista sobre a comunidade, entendendo que ambos propiciam meios de compreender o mundo enquanto atua-se nele. Assim, Collins debate duas controvérsias relacionadas à interseccionalidade. A primeira é como as experiências de vida são importantes para a teorização crítica, uma vez que os contextos estruturais impactam nas ações sociais; e a segunda é a necessidade de um vocabulário para analisar o mundo social de forma mais complexa do que aquela que o compreende como uma constelação de indivíduos.

O capítulo "Intersectionality and Question of Freedom" parte da premissa de que as teorias críticas lançam olhar atento para o tema da liberdade humana uma vez que ambicionam oporem-se às dominações políticas, bem como assume que diferentes ideias de liberdade informam diferentes projetos teóricos sobre o tema. Neste capítulo, face dos listados W. E. B. Du Bois, Ida Wells, Frantz Fanon, Stuart Hall, dentre outros, a liberdade é analisada a partir de duas autoras, Simone de Beauvoir e Pauli Murray, as quais expandem a concepção de opressão, por serem duas importantes intelectuais feministas engajadas ao existencialismo, pensamento social e político afro-americano e, em razão de seus distintos pontos de vista, permitem pensar novas possibilidades de liberdade as quais seriam de interesse para uma teoria da interseccionalidade. Collins destaca a liberdade como liberação e emancipação, metas dos ativistas da teoria da interseccionalidade.

A quarta e última parte do livro precede um simples epílogo que, de acordo com a autora, levanta mais perguntas do que necessariamente oferece respostas. São feitas perguntas que a comunidade e o coletivo de ativistas e pesquisadoras/es da interseccionalidade precisam responder de forma a torná-la uma teoria crítica social. Retoma a relacionalidade e a justiça social que são preconcebidas e assumidas, não necessariamente analisadas ou avaliadas, apesar de formarem a prática e a escola de pensamento da interseccionalidade. Collins pergunta como desenvolver as ferramentas de pesquisa da teoria da interseccionalidade de forma a avançar tanto a pesquisa como a práxis da teoria.

No capítulo "Relationality within Intersectionality" Collins examina o problema que é conceitualizar as dinâmicas de relacionalidade dentro das pesquisas de interseccionalidade. Afirma ser a relacionalidade tema central da interseccionalidade enquanto projeto teórico em construção. Explora porque o conceito de relacionalidade como interconexão entre diferentes projetos de dominação é mais efetivo em explicar opressão social do que outras construções teóricas de relacionalidade utilizadas. Também apresenta três modelos de pensamento relacional - adição, articulação e co-formação - que podem ser utilizados em análises teóricas da interseccionalidade propiciando um mapa provisório de navegação da relacionalidade dentro da teoria, modelos aos quais ela apresenta exemplos de utilização ao analisar a eugenia, compreendida como um projeto de conhecimento moderno de opressão transnacional.

No oitavo capítulo, "Intersectionality without social justice?", analisa os assumidos traços legítimos e característicos da interseccionalidade, destacadamente o comprometimento com a justiça social que deve ser percebida como característica central e constituinte da teoria. Contudo, essa característica central e constituinte não pode mais ser algo presumido na teoria, precisando ser construída. Por isso, o capítulo faz esse esforço de construção deste traço legítimo 
da teoria. O esforço em imaginar como a interseccionalidade funcionaria sem o compromisso com a justiça social são experimentados neste capítulo pois, de acordo com a autora, tornaria mais visível a necessidade vital do componente ético na teoria da interseccionalidade, o que preserva seu traço de nova teoria crítica social.

Por fim, em um breve epílogo, Collins busca retomar suas sistematizações para apresentar suas considerações, sem serem conclusivas. Destaca-se a descrição holística de interseccionalidade e as premissas que formam a teoria da interseccionalidade, a saber: a relacionalidade, o poder, a desigualdade social, o contexto social, a complexidade, e a justiça social. Pensando uma teoria que sustente tanto o pensamento crítico quanto a praxis, a autora faz as seguintes perguntas: o que é interseccionalidade?, como manter a interseccionalidade crítica?, existe alguma importância em observar o contexto?, como preservar objetividade?, como não incidir no extremo relativismo?, e, por fim, existe uma conexão inerente entre interseccionalidade e justiça social?

Chama a atenção que Collins apresenta a interseccionalidade como uma escola de pensamento complexa e sofisticada em razão da natureza guarda-chuva e residual que the competiria. Collins afirma que teorizar e praticar a interseccionalidade envolve um constante autoquestionamento das relações de poder e do status quo social a partir do ponto de vista dos grupos subordinados na situação relacionalmente observada.

Assim, não sendo algo dado e estático, essa premissa metodológica da interseccionalidade exige o debate sobre disputas e violências epistêmicas em todas as suas manifestações, o que em países com baixíssimo índice democrático e de desenvolvimento pode manifestar-se, inclusive, como violência letal. Apesar dos desafios, somente a autorreflexão permanente das/ os pensadoras/es acadêmicas/os e ativistas da interseccionalidade podem proteger a teoria de uma dogmatização que implicaria a gentrificação e descaracterização do projeto que the deu origem.

\section{Referências}

BILGE, Sirma; COLLINS, Patricia Hill. Intersectionality. Cambridge: John Wiley \& Sons, 2016.

BILGE, Sirma. "Intersectionality Undone. Saving Intersectionality from Feminist intersectionality Studies". Du Bois Review: Social Science Research on Race. Cambridge, v. 10, n. 2, p. 405-424, 2013.

COLLINS, Patricia Hill. Intersectionality as critical social theory. Durham and London: Duke University Press, 2019.

Ísis Aparecida Conceição (isisapc@unilab.edu.br) é Professora adjunta de Direito da UNILAB/Malês-BA. Professora Martin Flynn Global Law Faculty UCONNLaw. Pós-doutoranda em Direito do Estado na FD/USP. Doutora em Direito do Estado pela FD/USP, Mestra em Teoria Crítica Racial pela UCLA/Law. Mestra em Direito do Estado pela FD/USP. Especialista (latu sensu) em Direitos Humanos pela FD/USP e MPU. Bacharel Direito UNESP/Franca. 


\section{COMO CITAR ESTE ARTIGO DE ACORDO COM AS NORMAS DA REVISTA}

CONCEIÇÃO, Ísis Aparecida. "O que é necessário para que a Interseccionalidade possa vir a ser?". Revista Estudos Feministas, Florianópolis, v. 29, n. 2, e76404, 2021.

\section{CONTRIBUIÇĀO DE AUTORIA}

Não se aplica.

\section{FINANCIAMENTO}

Não se aplica.

\section{CONSENTIMENTO DE USO DE IMAGEM}

Não se aplica.

\section{APROVAÇĀO DE COMITÊ DE ÉTICA EM PESQUISA}

Não se aplica.

\section{CONFLITO DE INTERESSES}

Não se aplica.

\section{LICENÇA DE USO}

Este artigo está licenciado sob a Licença Creative Commons CC-BY 4.0 International. Com essa licença você pode compartilhar, adaptar, criar para qualquer fim, desde que atribua a autoria da obra.

\section{HISTÓRICO}

Recebida em 13/08/2020

Aprovada em 21/08/2020 